\title{
The Metabolism of D-Arabinose by Salmonella typhimurium
}

\author{
By DAVID C. OLD \\ Department of Bacteriology, University of Dundee, \\ Dundee $D D_{2}$ I $U B$ \\ AND ROBERT P. MORTLOCK \\ Department of Microbiology, University of Massachusetts, \\ Amherst, Massachusetts o1003, U.S.A. \\ (Received 30 December 1976; revised 22 April 1977)
}

\section{INTRODUCTION}

Little is known about the use of pentoses and pentitols by Salmonella typhimurium apart from a report by Gutnick et al. (I969) with S. typhimurium LT-2. Old (I977) showed that only D-ribose, L-arabinose and L-fucose were used as sole carbon sources by wild-type strains representative of the primary biotypes of Duguid et al. (1975). Although D-arabinose was not used as sole carbon source by wild-type strains, D-Ara ${ }^{+}$mutants were isolated from all strains incubated for 2 to 3 days in peptone water containing D-arabinose (Old, 1977). This work compares the mechanism of D-arabinose utilization by D-Ara ${ }^{+} S$. typhimurium strains with those previously established for other enterobacteria.

\section{METHODS}

Bacteria. Salmonella typhimurium strains were selected from the series of Duguid et al. (1975). Strains $\mathbf{8} 84$ (biotype Ia), si 836 (biotype 17a) and S2764 (biotype 25e) used L-fucose as sole carbon source and fermented D-arabinose in peptone water cultures (Old, 1977). Strain \$2626 (biotype 17bf) did not utilize L-fucose as sole carbon source and did not ferment $\mathrm{D}$-arabinose.

Media. Peptone water was $\mathrm{I} \cdot 5 \%(\mathrm{w} / \mathrm{v})$ Bacto-peptone (Difco) containing, when required, $0.5 \%(\mathrm{w} / \mathrm{v})$ D-arabinose. The two mineral salts media used were the medium of Le Blanc \& Mortlock (1971 $a$ ) and the basal medium of Davis \& Mingioli (1950), subsequently referred to as MMA and MMB respectively. Casein hydrolysate medium (CH) was MMA supplemented at $5 \mathrm{~g} \mathrm{l}^{-1}$ with casein hydrolysate (Nutritional Biochemicals, Cleveland, Ohio, U.S.A.). Carbon sources were added to all media at $5 \mathrm{~g} \mathrm{l}^{-1}$.

Isolation of mutants. D-Ara ${ }^{+}$mutants were isolated from s844, $\mathbf{s 1} 836$ and $\mathrm{s} 2764$ by culture of the wild-type strains in MMB plus D-arabinose in aerated, shaken cultures at $37^{\circ} \mathrm{C}$ for $48 \mathrm{~h}$. D-Ara ${ }^{+}$mutants, s844.da I, SI 836.daI and S2764.daI, were of the same full biotype as their parent strains. Mutants S2626.lfI, S2626.lf2 and s2626.lf6, utilizing L-fucose as sole carbon source, were isolated from $\mathbf{2 2 6 2 6}$ after prolonged culture in peptone water plus L-fucose.

Culture conditions. Bacteria were assayed for D-arabinose enzyme activities after growth under three cultural conditions: (i) aerated, shaken cultures grown at $37^{\circ} \mathrm{C}$ to late-exponential phase in $20 \mathrm{ml} \mathrm{CH}$ with or without L-fucose or D-arabinose; (ii) aerobic, static cultures grown in $120 \mathrm{ml}$ peptone water plus D-arabinose (in $5 \mathrm{ml}$ portions) for $24 \mathrm{~h}$ at $37^{\circ} \mathrm{C}$; (iii) aerated, shaken cultures grown in $25 \mathrm{ml}$ MMA plus D-arabinose for $24 \mathrm{~h}$ at $37^{\circ} \mathrm{C}$.

Growth was followed in side-arm flask cultures on a Klett-Summerson photocolorimeter (Klett Manufacturing Co., New York, U.S.A.) with a red $(660 \mathrm{~nm})$ filter.

Bacteria were harvested by centrifuging at $12000 \mathrm{~g}$ for $10 \mathrm{~min}$ at $4{ }^{\circ} \mathrm{C}$, washed in $10 \mathrm{ml}$ distilled water and suspended in Io mM-Tris/ $/ \mathrm{HCl}\left(\mathrm{pH} \mathrm{7.5)}\right.$ buffer containing I mM-mercaptoethanol and $0.1 \mathrm{mM}-\mathrm{MgCl}_{2}$.

Preparation of extracts. Bacteria were disrupted at $4{ }^{\circ} \mathrm{C}$ by two $15 \mathrm{~s}$ pulses in a Biosonik sonicator with an interval of $20 \mathrm{~s}$ and then centrifuged at $27000 \mathrm{~g}$ for $15 \mathrm{~min}$.

Enzyme activities. L-Fucose isomerase (D-arabinose isomerase; EC 5.3.1.3) activity was determined by using purified ribitol dehydrogenase (EC I.I.1.56) from Klebsiella pneumoniae strain w-70 to catalyse the reduction of L-fuculose (D-ribulose), as described by Oliver \& Mortlock (197I b). L-Fuculokinase 
(D-ribulokinase; EC 2.7.1.5I) activity was determined by measuring ADP formation with the pyruvate kinase-lactate dehydrogenase coupled system, as described by Le Blanc \& Mortlock (1971 $a$ ) and Oliver \& Mortlock (1971 $a$ ).

The protein content of cell-free extracts was measured by the method of Gornall, Bardawill \& David (1949).

Other assays. Glycollate was measured by its reaction with chromotropic acid (Le Blanc, I970). D-Arabinose was determined by the orcinol method (Mejbaum, 1939).

Chemicals. L-Fuculose and D-ribulose were prepared as described by Le Blanc \& Mortlock (I97Ia). All other chemicals and reagents were from commercial sources.

\section{RESULTS}

Extracts of wild-type D-Ara- $S$. typhimurium strains and their D-Ara ${ }^{+}$mutants grown in $\mathrm{CH}$ medium plus $\mathrm{L}$-fucose showed L-fucose isomerase and L-fuculokinase activities. The isomerase utilized either $\mathrm{L}$-fucose or $\mathrm{D}$-arabinose as substrate and the kinase was active with either L-fuculose or D-ribulose as substrate (Table I). As these activities were not induced in $\mathrm{D}-\mathrm{Ara}^{+}$bacteria grown in $\mathrm{CH}$ medium without L-fucose, the mutation allowing their growth on $D$-arabinose could not be due to the constitutive synthesis of these enzyme activities.

Incubation in $\mathrm{CH}$ medium plus $\mathrm{D}$-arabinose induced these activities in $\mathrm{D}$-Ara ${ }^{+}$bacteria but not in $\mathrm{D}^{-\mathrm{Ara}^{-}}$bacteria. The levels of induction were low but this may have been because the bacteria grew well enough on the casein hydrolysate to keep the levels of enzyme low due to a poorer induction rate with D-arabinose incubation. None of the wildtype $S$. typhimurium strains grown in peptone water plus $\mathrm{D}$-arabinose (without aeration) contained detectable amounts of L-fucose isomerase or L-fuculokinase activities whereas extracts from D-Ara ${ }^{+}$bacteria similarly grown had appreciable levels of both. The enzymes were also demonstrated in $\mathrm{D}$-Ara ${ }^{+}$bacteria grown in MMA medium plus D-arabinose.

The ratio of the specific activity of the isomerase with L-fucose as substrate to that with D-arabinose as substrate was $\mathrm{I} \cdot 8$ to $2 \cdot 0$, and the ratio of the specific activities of the kinase with L-fuculose and D-ribulose as substrates was 2.8 to 3.0 (Table I). These ratios were similar regardless of whether the enzymes were induced in D-Ara- bacteria by L-fucose or in D-Ara ${ }^{+}$bacteria by L-fucose or D-arabinose (Table I; unpublished observations). When tested at saturating substrate levels, the reaction velocity of the isomerase with L-fucose was about twice that with D-arabinose and that of the kinase with L-fuculose was nearly three times that with D-ribulose. The combined reaction rates with L-fucose and D-arabinose as substrates (or with L-fuculose and D-ribulose) were not additive. The observations are consistent with the proposal that a single isomerase and a single kinase are each involved with the oxidation of two substrates.

The typical D-Ara ${ }^{+}$mutant S2764.daI was grown on MMA medium plus D-arabinose in aerated shaken culture, and at intervals during the exponential growth period, samples of the growth medium were assayed for the presence of glycollate and D-arabinose. The concentration of D-arabinose declined over a $9 \mathrm{~h}$ period and in the first $6 \mathrm{~h}$ of growth there was a parallel accumulation of glycollate. Thereafter the concentration of glycollate declined and after $9 \mathrm{~h}$ glycollate and $\mathrm{D}$-arabinose were present in only trace amounts.

Salmonella typhimurium s2626 was unusual among the wild-type strains tested in that it did not utilize L-fucose as sole carbon source. Extracts of \$2626 grown on $\mathrm{CH}$ medium with or without L-fucose showed no detectable levels of isomerase or kinase activities. The L-fuculose-I-phosphate aldolase status of the strain was not determined. Extracts of L-fucose-utilizing mutants of this strain (\$2626. If $\mathrm{I}$, -1f2 and -lf6) grown in CH medium plus L-fucose showed L-fucose (D-arabinose) isomerase and L-fuculose (D-ribulose) kinase activities; the specific activity ratios for their respective substrates were similar to those already described. Thus, the acquisition of the ability to grow on L-fucose was accompanied by the ability to synthesize both isomerase and kinase enzymes in the presence of $\mathrm{L}$-fucose. 
Table I. Isomerase and kinase specific activities in cell-free extracts of wild-type Salmonella typhimurium strains and D-arabinose-utilizing mutants

Specific enzyme activities are expressed as $\mu$ mol NADH oxidized $\min ^{-1}$ (mg protein) ${ }^{-1}$.

\begin{tabular}{|c|c|c|c|c|c|}
\hline \multirow[b]{2}{*}{ Strain no.* } & \multirow[b]{2}{*}{ Growth medium $\dagger$} & \multicolumn{2}{|c|}{ Isomerase } & \multicolumn{2}{|c|}{ Kinase } \\
\hline & & D-Arabinose & L-Fucose & D-Ribulose & L-Fuculose \\
\hline $\begin{array}{l}\text { s844(-) } \\
\text { s844(-) } \\
\text { s844.daI(+) } \\
\text { s844.daI(+) }\end{array}$ & $\begin{array}{l}\text { CH } \\
\text { L-Fuc.CH } \\
\text { CH } \\
\text { L-Fuc.CH }\end{array}$ & $\begin{array}{c}<0.007 \ddagger \\
0.484 \\
<0.018 \\
0.305\end{array}$ & $\begin{array}{r}<0.009 \\
0.938 \\
<0.019 \\
0.643\end{array}$ & $\begin{array}{r}<0.003 \\
0.108 \\
<0.005 \\
0.066\end{array}$ & $\begin{array}{r}<0.003 \\
0.296 \\
<0.005 \\
0.173\end{array}$ \\
\hline $\begin{array}{l}\text { si836(-) } \\
\text { si 836(-) } \\
\text { si836.dai( }+) \\
\text { si836.dai( }+)\end{array}$ & $\begin{array}{l}\text { CH } \\
\text { L-Fuc.CH } \\
\text { CH } \\
\text { L-Fuc.CH }\end{array}$ & $\begin{array}{r}<0.003 \\
0.782 \\
<0.003 \\
0.570\end{array}$ & $\begin{array}{r}<0.010 \\
1.240 \\
<0.009 \\
1.040\end{array}$ & $\begin{array}{r}<0.006 \\
0.086 \\
<0.003 \\
0.158\end{array}$ & $\begin{array}{r}<0.006 \\
0.321 \\
<0.003 \\
0.406\end{array}$ \\
\hline $\begin{array}{l}\text { s2764(-) } \\
\text { s2764(-) } \\
\text { s2764.daI (+) } \\
\text { s2764.daI }(+)\end{array}$ & $\begin{array}{l}\mathrm{CH} \\
\text { L-Fuc.CH } \\
\text { CH } \\
\text { L-Fuc.CH }\end{array}$ & $\begin{array}{r}<0.007 \\
0.564 \\
<0.010 \\
0.542\end{array}$ & $\begin{array}{r}<0.005 \\
1.060 \\
<0.007 \\
I .024\end{array}$ & $\begin{array}{r}<0.004 \\
0.118 \\
<0.005 \\
0.142\end{array}$ & $\begin{array}{r}<0.004 \\
0.300 \\
<0.005 \\
0.400\end{array}$ \\
\hline
\end{tabular}

Furthermore, the L-Fuc ${ }^{+}$mutants, unlike s2626, fermented D-arabinose in 2 to 3 days in peptone water cultures.

\section{DISCUSSION}

There are two different pathways for D-arabinose metabolism by enterobacteria (Mortlock, 1976). In $\mathrm{D}-\mathrm{Ara}^{+}$K. pneumoniae, the mutation allowing D-arabinose utilization is associated with the constitutive synthesis of an L-fucose isomerase acting on L-fucose and D-arabinose (Camyre \& Mortlock, 1965; Oliver \& Mortlock, I97I $a, b$ ). Isomerization of D-arabinose to D-ribulose by L-fucose isomerase induces synthesis of D-ribulokinase which phosphorylates D-ribulose to produce D-ribulose 5-phosphate (Mortlock \& Wood, 1964a, b). Further metabolism takes place via the pentose phosphate pathway.

On the other hand, in D-Ara ${ }^{+}$Escherichia coli, D-arabinose induces the synthesis of three enzymes normally associated with L-fucose catabolism, and all three display dual substrate activities. As in $K$. pneumoniae, $\mathrm{L}$-fucose isomerase converts $\mathrm{D}$-arabinose to D-ribulose (Le Blanc \& Mortlock, I97I $b$ ) which is then converted to D-ribulose I-phosphate by L-fucolokinase, to be cleaved by L-fuculose-I-phosphate aldolase to dihydroxyacetone phosphate and glycolaldehyde (Le Blanc \& Mortlock, I97I $a, b$ ). D-Ara ${ }^{+} K$. pneumoniae strains deficient in D-ribulokinase also metabolize D-arabinose by the D-ribulose I-phosphate route to glycolaldehyde (Le Blanc \& Mortlock, 1972).

Incubation of $\mathrm{D}-\mathrm{Ara}^{+} S$. typhimurium in the presence of $\mathrm{L}$-fucose or D-arabinose induced the synthesis of L-fucose isomerase and L-fuculokinase which in other enterobacteria convert D-arabinose to D-ribulose I-phosphate. The ratios of the specific activities of these enzymes for their substrates were similar regardless of whether their synthesis had been induced in D-Ara ${ }^{+}$strains by growth in the presence of D-arabinose or L-fucose or in D-Ara- ${ }^{-}$strains by L-fucose. This suggested that in $S$. typhimurium these enzymes had dual substrate activities as noted in $E$. coli and $K$. pneumoniae. From our knowledge of the metabolism of $\mathrm{D}$-arabinose by these latter bacteria, the most likely route of D-arabinose degradation by $\mathrm{D}-\mathrm{Ara}^{+} S$. typhimurium would seem to be via D-ribulose I-phosphate.

Due to the presence of L-fuculose-I-phosphate aldolase, D-Ara ${ }^{+} E$. coli and D-Ara ${ }^{+}$ 
D-ribulokinase-deficient $K$. pneumoniae form glycolaldehyde and dihydroxyacetone phosphate from D-ribulose I-phosphate, and when grown on D-arabinose as sole carbon source, glycollic acid accumulates in the medium (Le Blanc \& Mortlock, 197I $b, 1972$ ). D-Ara ${ }^{+}$ $S$. typhimurium grown similarly also accumulates glycollic acid. Thus, although we did not demonstrate the synthesis of L-fuculose- I-phosphate aldolase, its presence may be inferred if it is accepted that D-arabinose is metabolized via the D-ribulose $\mathrm{I}$-phosphate route.

Escherichia and Salmonella are considered to be more closely related to each other than either is to Klebsiella (Krieg \& Lockhart, 1966). Because both E. coli and S. typhimurium lack a functional ribitol pathway (Le Blanc, 1970; Old, 1977) neither is likely to degrade $D$-arabinose by the D-ribulose 5 -phosphate route used by most klebsiellae. The similar growth responses of Escherichia and Salmonella on pentoses and pentitols and the indication that both degrade D-arabinose by similar mechanisms are not surprising in view of their taxonomic relatedness by other criteria.

This investigation was supported by Public Health Service Grant AI-06848 (to R.P.M.) from the National Institute of Allergy and Infectious Diseases, U.S.A. Financial support (to D.C.O.) by funds from The Royal Society and The Wellcome Trust is acknowledged with gratitude.

\section{REFERENCES}

Camyre, K. P. \& Mortlock, R. P. (1965). Growth of Aerobacter aerogenes on $\mathrm{D}$-arabinose and $\mathrm{L}-$ xylose. Journal of Bacteriology 90, I I $57-1$ I 58.

Davis, B. D. \& Mingioli, E.S. (I950). Mutants of Escherichia coli requiring methionine or vitamin $\mathrm{B}_{12}$. Journal of Bacteriology 60, 17-28.

Duguid, J. P., Anderson, E. S., Alfredsson, G. A., BARKER, R. \& OLD, D. C. (1975). A new biotyping scheme for Salmonella typhimurium and its phylogenetic significance. Journal of Medical Microbiology 8, 149-166.

Gornall, A. G., Bardawill, C. J. \& David, M. M. (I949). Determination of serum protein by means of the biuret reaction. Journal of Biological Chemistry $177,75 \mathrm{I}-766$.

Gutnick, D., Calvo, J. M., Klopotowski, T. \& Ames, B. N. (1969). Compounds which serve as the sole source of carbon or nitrogen for Salmonella typhimurium LT-2. Journal of Bacteriology roo, $215-219$.

KRIEG, R. E. \& Lockhart, W. R. (1966). Classification of enterobacteria based on overall similarity. Journal of Bacteriology 92, I 275- 1280.

LE BlanC, D. J. (1970). Pathways of D-arabinose degradation among coliforms. Ph.D. thesis, University of Massachusetts, U.S.A.

Le Blanc, D. J. \& Mortlock, R. P. (I97I $a$ ). Metabolism of D-arabinose: origin of a D-ribulokinase activity in Escherichia coli. Journal of Bacteriology 106, 82-89.

Le Blanc, D. J. \& Mortlock, R. P. (I97I $b$ ). Metabolism of D-arabinose: a new pathway in Escherichia coli. Journal of Bacteriology 106, 90-96.
Le Blanc, D. J. \& Mortlock, R. P. (1972). The metabolism of D-arabinose: alternate kinases for the phosphorylation of D-ribulose in Escherichia coli and Aerobacter aerogenes. Archives of Biochemistry and Biophysics $\mathbf{5 0}, 774-78 \mathrm{I}$.

Mejbaum, W. (1939). Uber die Bestimmung kleiner Pentosemengen, insbesondere in Derivaten der Adenylsäure. Zeitschrift für physiologische Chemie 258, I 1 7-I 20.

MorTLOCK, R. P. (1976). Catabolism of unnatural carbohydrates by microorganisms. Advances in Microbial Physiology 13, I-53.

Mortlock, R. P. \& Wood, W. A. (1964a). Metabolism of pentoses and pentitols by Aerobacter aerogenes. I. Demonstration of pentose isomerase, pentulokinase and pentitol dehydrogenase enzyme families. Journal of Bacteriology 88, 838-844.

MoRTlock, R. P. \& WoOD, W. A. (1964b). Metabolism of pentoses and pentitols by Aerobacter aerogenes. II. Mechanism of acquisition of kinase, isomerase and dehydrogenase activity. Journal of Bacteriology 88, 845-849.

OLD, D. C. (I977). The utilization of pentoses and pentitols by different biotypes of Salmonella typhimurium. Journal of General Microbiology Ior, 337-339.

Oliver, E. J. \& Mortlock, R. P. (1971 $a$ ). Growth of Aerobacter aerogenes on D-arabinose: origin of the enzyme activities. Journal of Bacteriology I08, 287-292.

Oliver, E. J. \& Mortlock, R. P. (I97I $b$ ). Metabolism of D-arabinose by Aerobacter aerogenes: purification of the isomerase. Journal of Bacteriology 108, 293-299. 